\title{
Pemodelan Derajat Kesehatan Menggunakan Structural Equation Modeling di Kabupaten Kediri
}

\author{
Amin Tohari \\ Universitas Nusantara PGRI Kediri \\ Jl. KH. Achmad Dahlan No. 76 Kota Kediri \\ e-mail: amin.tohari@ unpkediri.ac.id
}

\begin{abstract}
ABSTRAK
Situasi derajat kesehatan di Kabupaten Kediri pada tahun 2015 menunjukkan bahwa kedudukan Akngka Kematian Ibu (AKI) sama dengan angka tahun sebelumnya, sedangkan kondisi Angka Kematian Bayi (AKB) cenderung menurun dibandingkan dengan tahun 2013. Derajat kesehatan dan faktor-faktor yang mempengaruhi merupakan variabel laten yang membutuhkan indikator untuk mengukurnya, sehingga memerlukan metode analisis multivariate yang mengakomodir hubungan antar variabel laten yaitu structural equation modeling (SEM). SEM-PLS dapat digunakan ukuran sampel yang kecil, dan tidak mengharuskan berdistribusi multivariate normal. Penelitian ini menggunakan data skunder yang diambil dari dinas kesehatan Kabupaten Kediri yang terangkum dalam profil kesehatan Kabupaten Kediri tahun 2015, kemudian diolah menggunakan SmartPLS. Hasil penelitian menunjukkan bahwa lingkungan, perilaku masyarakat, dan pelayanan kesehatan berpengaruh negatif dan signifikan.
\end{abstract}

Kata kunci : structural equation modeling, derajat kesehatan, kabupaten kediri.

ABSTRACT

The health status of District Kediri in 2015 show that position of Maternal Mortality Rate is the same as the previous year, while the condition of Infant Mortality Rate tends to decrease compared to 2013. Health degree and influencing factors are latent variables requires an indicator to measure it, requiring a multivariate analysis method that accommodates the relationship between latent variables i.e. structural equation modeling (SEM). SEM-PLS can be used small sample size, and does not require normal multivariate distribution. This study uses secondary data taken from health office of District Kediri which summarized in health profile of Regency of Kediri in 2015, then processed using SmartPLS. The results showed that the environment, behavior of society, and health services have a negative and significant effect.

Keywords : structural equation modeling, health status, district kediri.

\section{PENDAHULUAN}

Upaya kesehatan merupakan kegiatan yang dilakukan secara terpadu, terintegrasi, dan berkesinambungan untuk memelihara serta meningkatkan derajat kesehatan masyarakat dalam bentuk pencegahan penyakit, dan pemulihan kesehatan oleh pemerintah dan masyarakat (Undang-Undang Kesehatan Nomor 36 Tahun 2009). Berakhirnya Millenium Development Goals (MDGs) pada tahun 2015 menunjukkan target Nasional yang belum sepenuhnya tercapai termasuk Angka Kematian Ibu (AKI) dan Angka Kematian Bayi (AKB) yang merupakan indikator derajat kesehatan. Demikian juga yang terjadi di Kabupaten Kediri, pada tahun 2015 kedudukan AKI sama dengan angka tahun sebelumnya. Sedangkan kondisi AKB di Kabupaten Kediri pada tahun 2015 cenderung menurun dibandingkan dengan tahun 2013 (Dinkes, 2016).

Menurut Effendy (2000), derajat kesehatan merupakan sebuah konsep dari teori Blum yang menyatakan bahwa derajat kesehatan dipengaruhi lingkungan, perilaku masyarakat, dan pelayanan kesehatan. Derajat kesehatan sangat penting dalam menggambarkan profil kesehatan masyarakat di suatu

Amin Tohari / J Statistika : Jurnal Imiah dan Aplikasi Statistika Vol. 10, No. 2 
daerah. Dalam menilai derajat kesehatan masyarakat yang merupakan variabel laten endogen, Talangko (2009) menggunakan indikator jumlah kematian bayi, jumlah kematian balita, jumlah kematian ibu, morbiditas, dan status gizi buruk balita.

Penggunaan variabel yang berbentuk laten atau konstruk yang dibangun dari beberapa variabel manifes atau indikator, memerlukan metode analisis multivariate yang mengakomodir hubungan antar variabel laten yaitu structural equation modeling (SEM). Pada hakekatnya pengembangan model dalam SEM adalah pencarian atau pengembangan sebuah model yang mempunyai justifikasi teoritis yang kuat, sehingga kajian teori yang mendalam untuk mendapatkan sebuah justifikasi teoritis untuk model yang akan diuji adalah syarat mutlak dalam SEM (Ferdinand, 2005). Lebih lanjut Ghozali (2013) mengungkapkan bahwa SEM merupakan gabungan dari analisis faktor dan analisis jalur (path analysis) menjadi satu metode statistika yang komprehensif. Secara umum, terdapat Structural equation modeling (SEM) yang berbasis covariance dan ada juga SEM yang berbasis variance atau yang lebih dikenal dengan Partial Least Square (PLS). SEMPLS merupakan metode analisis yang powerfull dan flexibel karena sifatnya yang dapat digunakan untuk berbagai skala pengukuran data (nominal, ordinal, interval, dan rasio), dapat digunakan untuk ukuran sampel yang kecil, dan tidak mengharuskan berdistribusi multivariate normal (Esteves et al., 2003).

Analisis jalur dalam SEM-PLS terdiri dari tiga set hubungan sebagai berikut (Ghozali \& Latan, 2012):

1. Model Struktural (Inner Model)

Model struktural atau Inner model merupakan model yang menunjukkan hubungan atau kekuatan estimasi antar variabel laten atau konstruk berdasarkan pada teori substantif.

Model persamaannya adalah sebagai berikut (Jaya \& Sumertajaya, 2008) :

$$
\boldsymbol{\eta}=\mathbf{B} \boldsymbol{\eta}+\boldsymbol{\Gamma} \boldsymbol{\xi}+\boldsymbol{\zeta}
$$

dengan : $\boldsymbol{\eta}=$ vektor laten endogen

$\xi=$ vektor laten eksogen

$\zeta=$ vektor residual (unexplained variance)

$\mathbf{B}=$ Matrik koefisien pengaruh laten endogen terhadap laten endogen

$\boldsymbol{\Gamma}=$ Matrik koefisien pengaruh laten eksogen terhadap laten endogen

Pada dasarnya PLS didesain untuk model recursive (model yang mempunyai satu arah kausalitas), sehingga hubungan antara variabel laten endogen sering disebut dengan causal chain system (hubungan sistem berantai) yang dapat dispesifikasikan sebagai berikut (Jaya \& Sumertajaya, 2008):

$$
\eta_{j}=\sum_{i} \beta_{j i} \eta_{i}+\sum_{b} \gamma_{j b} \xi_{b}+\zeta_{j}
$$

dengan: $j$ =banyaknya variabel endogen dalam persamaan struktural

$i$ =indeks dari 1 sampai dengan banyaknya variabel endogen yang menjadi variabel eksogen pada persamaan struktural

$b$ =indeks dari 1 sampai dengan banyaknya variabel eksogen

2. Model Pengukuran (Outer Model)

Model pengukuran atau outer model model yang menunjukkan bagaimana setiap blok indikator berhubungan dengan variabel latennya.

Model persamaan untuk outer model reflective adalah sebagai berikut (Jaya \& Sumertajaya, 2008) :

$$
\begin{aligned}
& \mathbf{x}=\boldsymbol{\Lambda}_{x} \boldsymbol{\xi}+\boldsymbol{\delta}_{x} \\
& \mathbf{y}=\boldsymbol{\Lambda}_{y} \boldsymbol{\eta}+\boldsymbol{\varepsilon}_{y}
\end{aligned}
$$

dimana $\mathbf{x}$ dan $\mathbf{y}$ adalah vektor manifest variabel atau indikator untuk konstruk laten eksogen ( $\boldsymbol{\xi})$ dan endogen ( $\boldsymbol{\eta}), \boldsymbol{\Lambda}_{x}$ dan $\boldsymbol{\Lambda}_{y}$ adalah matriks loading yang menggambarkan koefisien yang menghubungkan variabel laten dengan indikatornya, serta $\boldsymbol{\varepsilon}_{x}$ dan $\boldsymbol{\varepsilon}_{y}$ yang merupakan residual kesalahan pengukuran (measurement error).

Untuk outer model formative dengan persamaan sebagai berikut (Jaya \& Sumertajaya, 2008):

$$
\begin{aligned}
& \boldsymbol{\xi}=\boldsymbol{\Pi}_{\xi} \mathbf{x}+\boldsymbol{\delta}_{\xi} \\
& \boldsymbol{\eta}=\boldsymbol{\Pi}_{\eta} \mathbf{y}+\boldsymbol{\varepsilon}_{\eta}
\end{aligned}
$$

dimana $\boldsymbol{\xi}$ dan $\boldsymbol{\eta}$ adalah vektor konstruk laten eksogen dan endogen, $\mathbf{x}$ dan $\mathbf{y}$ adalah vektor manifest variabel atau indikator untuk konstruk laten eksogen $(\xi)$ dan endogen $(\boldsymbol{\eta}) . \boldsymbol{\Pi}_{\xi}$ dan $\boldsymbol{\Pi}_{\eta}$ adalah matriks loading yang merupakan koefisien hubungan untuk variabel laten dan blok indikator, serta $\boldsymbol{\delta}_{\xi}$ dan $\boldsymbol{\varepsilon}_{\eta}$ merupakan residual dari model pengukuran.

3. Bobot Penghubung (Weight Relations)

Model outer dan model inner memberikan spesifikasi yang diikuti dalam estimasi algorithma $P L S$. Sehingga dibutuhkan definisi weight relation untuk melengkapinya, yaitu 
sebagai bobot yang menghubungkan model outer dan model inner untuk membentuk estimasi variabel laten eksogen dan laten endogen.

Estimasi nilai kasus untuk setiap variabel laten yang diestimasi dalam PLS (Jaya \& Sumertajaya, 2008):

$$
\begin{gathered}
\hat{\xi}_{b}=\sum_{k b} w_{k b} x_{k b} \\
\hat{\eta}_{i}=\sum_{k i} w_{k i} y_{k i}
\end{gathered}
$$

dimana $w_{k b}$ dan $w_{k i}$ adalah $k$ weigth (bobot ke- $k$ ) yang digunakan untuk mengestimasi variabel laten $\xi_{b}$ dan $\eta_{i}$. Estimasi variabel laten adalah linear aggregate dari indikator yang nilai bobotnya didapat melalui prosedur estimasi $P L S$.

\section{METODE PENELITIAN}

Data penelitian ini merupakan data skunder yang diambil dari dinas kesehatan Kabupaten Kediri yang terangkum dalam profil kesehatan Kabupaten Kediri tahun 2015.

Variabel laten eksogen yang digunakan dalam penelitian ini adalah variabel lingkungan, variabel perilaku, dan variabel pelayanan kesehatan. Sedangkan variabel laten endogen adalah variabel laten yang diketahui dalam penelitian ini ada 1 (satu) variabel yaitu variabel derajat kesehatan.

Untuk mengukur variabel-variabel laten tersebut dikembangkan berbagai indikator, sebagai variabel manifest adalah sebagai berikut (Talangko, 2009):

a. Indikator dari variabel lingkungan adalah keluarga yang memiliki jamban sehat, keluarga yang mengakses air bersih, dan keluarga yang memiliki pengelolaan air limbah

b. Indikator untuk variabel perilaku adalah rumah tangga yang berperilaku hidup bersih dan sehat, peran aktif masyarakat dalam posyandu purnama dan mandiri, dan bayi yang mendapatkan ASI ekslusif

c. Indikator untuk variabel mutu pelayanan kesehatan adalah pertolongan persalinan oleh tenaga kesehatan, dan deteksi tumbuh kembang anak

d. Indikator untuk variabel derajat kesehatan adalah jumlah kematian bayi, jumlah kematian balita, jumlah kematian ibu, jumlah kesakitan, dan status gizi bayi dan balita

\section{HASIL DAN PEMBAHASAN Outer Model}

Evaluasi pada model pengukuran (outer model) melalui loading factor dilakukan untuk mengetahui validitas indikator dalam membentuk suatu variabel laten, dengan cara melihat nilai convergent validity indikator-indikator yang ada dalam model. Setiap indikator dalam model harus memenuhi convergent validity yaitu memiliki absolut loading factor $>0.5$, jika terdapat indikator yang tidak memenuhi kriteria convergent validity maka indikator tersebut dikeluarkan dari model. Berikut adalah hasil convergent validity:

Tabel 1. Hasil Akhir Convergent Validity putara 1

\begin{tabular}{|c|c|c|c|c|}
\hline Indikator & $\begin{array}{c}\text { Derajat } \\
\text { Kesehatan }\end{array}$ & Lingkungan & $\begin{array}{c}\text { Pelayanan } \\
\text { Kesehatan }\end{array}$ & Perilaku \\
\hline $\mathbf{x 1}$ & & 0.769218 & & \\
\hline $\mathbf{x 2}$ & & 0.787711 & & \\
\hline $\mathbf{x 3}$ & & 0.557048 & & \\
\hline $\mathbf{x 4}$ & & & & 0.713038 \\
\hline $\mathbf{x 5}$ & & & & 0.685379 \\
\hline $\mathbf{x 6}$ & & & & 0.000400 \\
\hline $\mathbf{x 7}$ & & & 0.290111 & \\
\hline $\mathbf{x 8}$ & & & 0.999500 & \\
\hline $\mathbf{y 1}$ & 0.721659 & & & \\
\hline $\mathbf{y 2}$ & 0.823130 & & & \\
\hline $\mathbf{y 3}$ & 0.448769 & & & \\
\hline $\mathbf{y 4}$ & -0.220673 & & & \\
\hline $\mathbf{y 5}$ & 0.542139 & & & \\
\hline
\end{tabular}

Sumber: Dinkes Kediri, 2016 (diolah)

Suatu indikator dikatakan memenuhi convergent validity, jika mempunyai nilai loading di atas 0,500 (Ghozali, 2006). Berdasarkan hasil yang diperoleh dari pengolahan data, indikator x6 pada variabel perilaku, indikator $\mathrm{x} 7$ pada variabel pelayanan kesehatan, indikator y3 dan y4 pada variabel derajat kesehatan memiliki outer loading yang lebih kecil dari 0,500 , sehingga indikator tersebut perlu dieliminasi dari model, kemudian dilakukan evaluasi terhadap indikator sisa. Berikut adalah hasil convergent validity putaran 2 :

Tabel 2. Hasil Akhir Convergent Validity putaran 2

\begin{tabular}{|c|c|c|c|c|}
\hline Indikator & $\begin{array}{c}\text { Derajat } \\
\text { Kesehatan }\end{array}$ & Lingkungan & $\begin{array}{c}\text { Pelayanan } \\
\text { Kesehatan }\end{array}$ & Perilaku \\
\hline $\mathbf{x 1}$ & & 0.777464 & & \\
\hline $\mathbf{x 2}$ & & 0.778275 & & \\
\hline
\end{tabular}




\begin{tabular}{|c|c|c|c|c|}
\hline Indikator & $\begin{array}{c}\text { Derajat } \\
\text { Kesehatan }\end{array}$ & Lingkungan & $\begin{array}{c}\text { Pelayanan } \\
\text { Kesehatan }\end{array}$ & Perilaku \\
\hline $\mathbf{x 3}$ & & 0.558632 & & \\
\hline $\mathbf{x 4}$ & & & & 0.744670 \\
\hline $\mathbf{x 5}$ & & & & 0.693248 \\
\hline $\mathbf{x 8}$ & & & 1.000 & \\
\hline $\mathbf{y 1}$ & 0.715849 & & & \\
\hline $\mathbf{y 2}$ & 0.773400 & & & \\
\hline $\mathbf{y 5}$ & 0.643188 & & & \\
\hline
\end{tabular}

Sumber: Dinkes Kediri, 2016 (diolah)

Berdasarkan tabel 2 di atas, semua indikator memiliki outer loading yang lebih besar dari 0,500, sehingga tidak ada indikator yang perlu dieliminasi dari model. Evaluasi model pengukuran (outer model) juga dapat dilihat berdasarkan average variance extracted (AVE) dan composite reliability. Berikut adalah hasil average variance extracted (AVE) dan composite reliability:

Tabel 3. Hasil Average Variance Extracted (AVE)

\begin{tabular}{|l|c|c|}
\hline \multicolumn{1}{|c|}{ Variabel } & AVE & $\begin{array}{c}\text { Composite } \\
\text { Reliability }\end{array}$ \\
\hline Derajat Kesehatan & 0.508093 & 0.754986 \\
\hline Lingkungan & 0.507411 & 0.402195 \\
\hline Pelayanan Kesehatan & 1.000 & 1.000 \\
\hline Perilaku & 0.517563 & 0.681820 \\
\hline
\end{tabular}

Sumber: Dinkes Kediri, 2016 (diolah)

Berdasarkan tabel 3 di atas dapat diketahui hasil nilai average variance extracted $(A V E)$ dan nilai composite reliability. Nilai $A V E$ yang direkomendasikan adalah nilai yang lebih besar dari 0.5 , hasil $A V E$ dari penelitian ini diketahui berada di bawah 0.5 yang berarti variansi yang dapat dijelaskan indikator adalah di bawah $50 \%$. Composite reliability bertujuan untuk menguji reliabilitas atau kekonsistenan variabel laten atau konstruk, dimana nilai composite reliability di atas 0.7 dapat dikatakan variabel laten memiliki reliabilitas yang baik. Berdasarkan tabel 3 di atas diketahui variabel-variabel laten dari penelitian ini tidak seluruhnya memiliki nilai composite reliability di atas 0.7 , ada beberapa variabel laten dengan composite reliability di bawah 0.7. Reliabilitas yang kurang baik dalam penelitian ini disebabkan oleh data yang digunakan oleh masing-masing peneliti merupakan data rasio berupa yaitu persentase bukan merupakan data persepsi.

\section{Inner Model}

Evaluasi model struktural (inner model) pada \$EM-PLS dapat diketahui dari goodness of fit atau R-Square $\left(\mathrm{R}^{2}\right)$. Hasil pengolahan data dengan menggunakan SmartPLS memberikan $R$-Square sebesar 0,365982. Secara teori disebutkan bahwa nilai $R$-Square diatas 0.67 dikatakan kontribusi variabel eksogen terhadap endogen adalah kuat, antara 0.33 sampai dengan 0.67 dikatakan memiliki kontribusi yang cukup/sedang dan antara 0.19 sampai dengan 0.33 dikatakan memiliki kontribusi yang lemah (Henseler et al., 2009).

Pada penelitian ini, $R$-Square menunjukkan seberapa besar model mampu menjelaskan variasi dari derajat kesehatan. Hasil penelitian menunjukkan $R$-Square antara 0.33 sampai dengan 0.67 yang berarti kontribusi variabel lingkungan, perilaku masyarakat dan pelayanan kesehatan terhadap derajat kesehatan dari penelitian ini adalah cukup/sedang.

\section{Hasil Model Struktural}

Dalam penelitian ini model struktural digunakan untuk mengetahui faktor-faktor yang mempengaruhi derajat kesehatan di Kabupaten Kediri. Hasil kausalitas faktor-faktor yang mempengaruhi derajat kesehatan di Kabupaten Kediri adalah sebagai berikut:

Tabel 4. Hasil Uji Kausalitas faktor-faktor yang mempengaruhi derajat kesehatan kabupaten kediri

\begin{tabular}{|l|c|c|c|}
\hline \multicolumn{1}{|c|}{ Kausal } & $\begin{array}{c}\text { Original } \\
\text { Sample } \\
(\mathbf{O})\end{array}$ & $\begin{array}{c}\text { Standard } \\
\text { Error } \\
\text { (STERR) }\end{array}$ & $\begin{array}{c}\text { T Statistics } \\
\text { (|O/STERR) }\end{array}$ \\
\hline $\begin{array}{l}\text { Lingkungan -> } \\
\text { Derajat Kesehatan }\end{array}$ & -0.192194 & 0.069211 & 2.776 .939 \\
\hline $\begin{array}{l}\text { Pelayanan } \\
\text { Kesehatan -> } \\
\text { Derajat Kesehatan }\end{array}$ & -0.316288 & 0.103781 & 3.047 .665 \\
\hline $\begin{array}{l}\text { Perilaku -> Derajat } \\
\text { Kesehatan }\end{array}$ & -0.408066 & 0.118117 & 3.454 .746 \\
\hline
\end{tabular}

Sumber: Dinkes Kediri, 2016 (diolah)

Hasil kausalitas penelitian ini juga dapat ditampilkan dalam bentuk gambar berikut ini: 


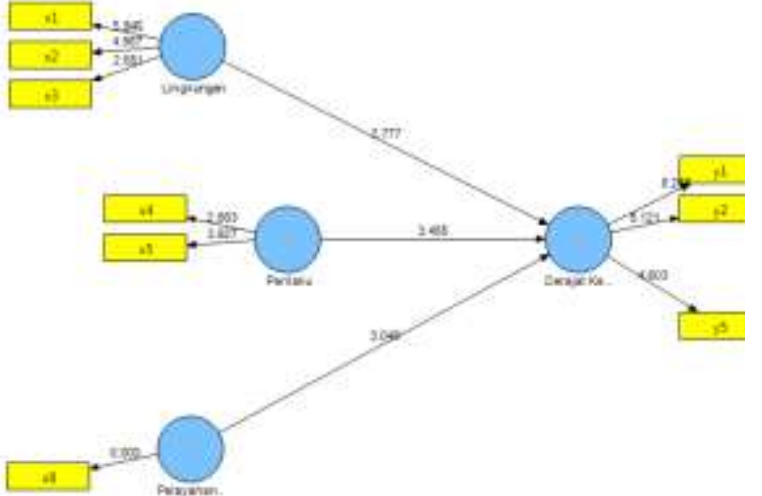

Gambar 1. Kausalitas faktor-faktor yang mempengaruhi derajat kesehatan kabupaten kediri

Bentuk umum model struktural penelitian ini adalah sebagai berikut :

$$
\eta=\gamma_{1} \xi_{1}+\gamma_{2} \xi_{2}+\gamma_{3} \xi_{3}+\zeta
$$

dengan $\eta=$ variabel laten endogen derajat kesehatan

$\gamma_{1}, \gamma_{2}$ dan $\gamma_{3}=$ koefisien hbungan langsung variable laten eksogen terhadap variabel laten endogen.

$\xi_{1}=$ variabel laten eksogen lingkungan

$\xi_{2}=$ variabel laten eksogen perilaku masyarakat

$\xi_{3}=$ variabel laten eksogen pelayanan kesehatan

$\zeta=$ galat model persamaan variabel laten endogen

Model struktural dari penelitian yang telah diasumsikan berdasarkan estimasi model derajat kesehatan adalah sebagai sebagai berikut : $\hat{\eta}=-0.192194 \xi_{1}-0.408066 \xi_{2}-0.316288 \xi_{3}$

Hipotesis yang diajukan dalam penelitian ini adalah sebagai berikut:

a. Lingkungan terhadap derajat kesehatan

$$
\begin{array}{llr}
H_{0}: \gamma_{1}=0, & \begin{array}{l}
\text { Lingkungan tidak } \\
\text { berpengaruh signifikan } \\
\text { terhadap derajat kesehatan }
\end{array} \\
H_{1}: \gamma_{1} \neq 0, & \begin{array}{l}
\text { Lingkungan berpengaruh } \\
\text { signifikan terhadap derajat } \\
\text { kesehatan }
\end{array}
\end{array}
$$

b. Perilaku masyarakat terhadap derajat kesehatan

$$
\begin{array}{ll}
H_{0}: \gamma_{2}=0, & \begin{array}{l}
\text { Perilaku masyarakat tidak } \\
\text { berpengaruh signifikan } \\
\text { terhadap derajat kesehatan }
\end{array} \\
H_{1}: \gamma_{2} \neq 0, & \begin{array}{l}
\text { Perilaku masyarakat } \\
\text { berpengaruh signifikan } \\
\text { terhadap derajat kesehatan }
\end{array} \\
\text { c. } \begin{array}{l}
\text { Pelayanan } \\
\text { kesehatan }
\end{array} & \begin{array}{l}
\text { kesehatan terhadap derajat } \\
H_{0}: \gamma_{3}=0,
\end{array} \\
H_{1}: \gamma_{3} \neq 0, & \begin{array}{l}
\text { Pelayanan kesehatan tidak } \\
\text { terhadap derajat kesehatan } \\
\text { berpengaruh signifikan } \\
\text { terhadap derajat kesehatan }
\end{array}
\end{array}
$$

Pengujian hipotesis dilakukan dengan melihat nilai $t$-statistics yang dibandingkan dengan nilai $t_{\text {tabel }}$ yaitu $t_{0.05,13}=2.160$. Jika t-statistics lebih besar dari $t_{\text {tabel }}$ maka tolak $\mathrm{H}_{0}$ yang berarti parameter signifikan (laten eksogen mempunyai pengaruh yang bermakna terhadap laten endogen) dan sebaliknya jika $t$-statistics lebih kecil dari $t_{\text {tabel }}$ maka gagal tolak $\mathrm{H}_{0}$ yang berarti parameter tidak signifikan (laten eksogen mempunyai pengaruh yang tidak bermakna terhadap laten endogen). bahwa :

Dari persamaan struktural dapat diketahui

a. Variabel laten eksogen lingkungan memiliki pengaruh negatif dan signifikan terhadap variabel laten endogen derajat kesehatan dengan estimasi koefisien jalur sebesar 0.192194 dan $t$-statistics 2,776939. Artinya semakin banyak keluarga yang memiliki jamban, keluarga yang mengakses air bersih dan keluarga yang memiliki pengelolaan air limbah maka pengukur derajat kesehatan yaitu jumlah kematian bayi, jumlah kematian balita, jumlah kematian ibu, jumlah kesakitan dan status gizi buruk balita akan semakin menurun.

b. Variabel laten eksogen perilaku masyarakat memiliki pengaruh negatif dan signifikan terhadap variabel laten endogen derajat kesehatan dengan estimasi koefisien jalur sebesar - 0.408066 dan t-statistics 3,454746. Artinya semakin banyak rumah tangga yang berperilaku hidup bersih dan sehat, semakin banyak peran aktif masyarakat dalam posyandu Purnama dan Mandiri, serta semakin banyak bayi yang mendapatkan ASI ekslusif maka pengukur derajat kesehatan yaitu jumlah kematian bayi, jumlah kematian balita, jumlah kematian ibu, jumlah kesakitan 
dan status gizi buruk balita akan semakin menurun.

c. Variabel laten eksogen pelayanan kesehatan memiliki pengaruh negatif dan signifikan terhadap variabel laten endogen derajat kesehatan dengan estimasi koefisien jalur sebesar - 0.316288 dan t-statistik seebsar 3.047665. Artinya semakin baik pertolongan persalinan oleh tenaga kesehatan dan deteksi tumbuh kembang anak yang merupakan indikator pelayanan kesehatan maka pengukur derajat kesehatan yaitu jumlah kematian bayi, jumlah kematian balita, jumlah kematian ibu, jumlah kesakitan dan status gizi buruk balita akan semakin menurun.

\section{KESIMPULAN DAN SARAN \\ Kesimpulan}

Uji kausalitas dari model Structural Equation Modeling (SEM) menunjukkan bahwa lingkungan, perilaku masyarakat, dan pelayanan kesehatan mempunyai pengaruh negatif dan signifikan terhadap derajat kesehatan. Artinya Semakin baik atau semakin banyak indikator-indikator variabel lingkungan, perilaku masyarakat, dan pelayanan kesehatan maka pengukur derajat kesehatan yaitu jumlah kematian bayi, jumlah kematian balita, jumlah kematian ibu, jumlah kesakitan dan status gizi buruk balita akan semakin menurun.

\section{Saran}

Berdasarkan hasil analisis dan kesimpulan, saran yang dapat diberikan dari penelitian ini adalah:

1. Untuk peneliti selanjutnya agar mengembangkan lagi model berdasarkan kerangka konseptual yang lebih detail, dengan menggali lebih luas variabel-variabel non kesehatan yang dapat berpengaruh terhadap derajat kesehatan misalnya pendidikan dan ekonomi sehingga dapat memberikan kontribusi yang lebih baik terhadap perkembangan pembangunan

2. Dinas terkait perlu memperhatikan variabel laten lingkungan dengan indikator keluarga yang memiliki jamban sehat, keluarga yang mengakses air bersih dan keluarga yang memiliki pengelolaan air limbah, variabel laten perilaku dengan indikator rumah tangga yang berperilaku hidup bersih dan sehat, peran aktif masyarakat dalam Posyandu Purnama dan Mandiri dan bayi yang mendapatkan ASI ekslusif, dan variabel laten pelayanan kesehatan dengan indikator pertolongan persalinan oleh tenaga kesehatan dan deteksi tumbuh kembang anak yang merupakan indikator pelayanan kesehatan agar jumlah kematian bayi, jumlah kematian balita, jumlah kematian ibu, orbiditas dan status gizi buruk semakin menurun.

\section{DAFTAR PUSTAKA}

Dinkes Kediri. 2016. Profil Kesehatan Kabupaten Kediri. Kediri: Dinas Kesehatan Kabupaten Kediri.

Effendy, N. 2000. Dasar-dasar Keperawatan Kesehatan Masyarakat. Jakarta: EGC.

Esteves, J., Casanovas, J., \& Pastor, J. 2003. Modeling with Partial Least Squares Critical Sucess Factor Interrelationships in ERP Implementations. Paper presented at the Ninth Americas Conference on Information Systems.

Ferdinand, A. 2005. Structural Equation Modeling dalam Penelitian Manajemen. Semarang: Badan Penerbit-Undip.

Ghozali, I. 2013. Model Persamaan Struktural Konsep dan Aplikasi dengan Program Amos 21.0. Semarang: Badan Penerbit Undip.

Ghozali, I., \& Latan, H. 2012. Partial Least Squares: Konsep, Teknik dan Aplikasi SmartPLS 2.0 M3. Semarang: Badan Penerbit Universitas Diponegoro.

Henseler, J. r., Ringle, C. M., \& Sinkovics, R. R. 2009. The Use of Partial Least Squares Path Modeling in International Marketing. New Challenges to International Marketing, Advances in International Marketing, 20, 277-319.

Jaya, I. G. N. M., \& Sumertajaya, I. M. 2008. Pemodelan Persamaan Struktural Dengan Partial Least Square. Paper presented at the Seminar Nasional Matematika dan Pendidikan Matematika 2008.

Talangko, L. P. 2009. Pemodelan Persamaan Structural dengan Maksimum Likelihood dan Bootstrap pada Derajat Kesehatan di Propinsi Sulawesi Selatan. (Magister), Institut Teknologi Sepuluh Nopember, Surabaya. (TESIS SS09 2304) 